\title{
Application of Cognitive Linguistics in English Vocabulary Teaching
}

\author{
Yan Zhao \\ Yantai Nanshan University \\ Yantai, Shandong, China 265706
}

\begin{abstract}
Vocabulary is very important to language, just like bricks to buildings. Without words, language has no meaning at all. The research on vocabulary acquisition and teaching has a history of thousands of years, however, teachers are still facing a huge challenge now, that is how to help students acquire the words quickly and effectively. This paper puts forward cognitive teaching strategy which has a new approach into vocabulary teaching. The new branch is based on embodied philosophy and it tries to interpret the lexical phenomenon with the theory of cognitive linguistics. According to the cognitive vocabulary learning strategy and teaching practice, the author proposes a cognitive vocabulary teaching strategy which is a great help for English teachers and vocabulary teaching.
\end{abstract}

Keywords-English vocabulary; cognitive linguistics; teaching strategy

\section{INTRODUCTION}

Vocabulary is the basis of language. "Without grammar very little can be conveyed; without vocabulary nothing can be conveyed" (Wilkins, 1976). Therefore vocabulary teaching as well as vocabulary study is of vital importance. Both teachers and students pay much attention on vocabulary teaching and vocabulary learning. Learners of EFL still find it exhausting to learn and memorize the vocabulary. In vocabulary leaning and teaching, appropriate strategies play an irreplaceable role. The research on vocabulary learning strategies is necessary and practical for all the EFL learners. For thousands of years, researchers have come up with many perspectives of vocabulary learning and teaching such as Grammar Translation Method, Audio-lingual Method. With the development of cognitive linguistics, scholars both at home and abroad explore a new vocabulary teaching method. It turns out that the new approach can keep with rules of human's cognitive development.

\section{COGNITIVE Linguistics’ EFFECT ON VOCABULARY TEACHING}

Cognitive linguistics, which emerged in the 1970s, is a sub branch as well as a newly established branch of linguistics and it regards language as an instrument to process, organize and convey information. Cognitive linguistics holds the belief that language is based on our bodily experience and the way we conceptualize the world. Cognitive linguistics has a major influence on English teaching including vocabulary teaching. It brings a whole new theoretical guide for vocabulary teaching.
Cognitive linguists, like Lakoff and Johnson, have intensive study on vocabulary. According to their study, we can get the idea that the senses of words are not random but based on people's experience with the outer world. Lakoff and Johnson put emphasis on the embodied mind, unconsciousness of cognition and metaphor. Besides, cognitive linguists also put forward the mapping principles which have a structure called "schema". With the help of "schema", we can understand the abstract sense on the basis of concrete sense. Cognitive linguists believe that the most essential experience of human is the understanding of his body, the function and structure of his body and the interacting with the outer world. Therefore, the body experience is the source for mapping of conceptual metaphor for concrete and abstract phenomena. A lot of theories proposed by cognitive linguistics are applied to vocabulary teaching, such as prototype category and image schema. Many teachers and scholars get enlightenment from the cognitive vocabulary teaching strategies and put the theories into the classroom practice. In the teaching practice, teachers can use cognitive theories to help students understand why a word has so many different meanings and the origin of its different meanings. The meaning of a word changed with human's exploitation with the world through the history. Moreover, the understanding of a word in a sentence depends on people's cognitive ability to some extent. Cognitive linguistics provides a new and special perspective for us to study linguistics, including vocabulary. Although the cognitive linguistics cannot solve all the problems in English vocabulary learning and teaching, it cannot be denied that it makes an irreplaceable contribution to English vocabulary teaching and learning.

\section{THEORETICAL FOUNDATION OF COGNITIVE ENGLISH VOCABULARY TEACHING}

\section{A. Prototype Theory}

Prototype is the center and core element of the category. In a category, "each item has at least one, and probably several elements in common with one or more other items, but no, or few elements are common to all items" (Rosch \& Mervis, 1975:575). Here is an illustration: 


$$
\begin{aligned}
& \text { Item Attribute Overlapping similarities } \\
& 1 \quad \text { AB } \quad \text { A } \\
& 2 \text { BC B C } \\
& 3 \text { CD } \quad \text { C D } \\
& 4 \text { DE } \text { D E } \\
& \text { (Ungerer \& Schmid, 2008:29) }
\end{aligned}
$$

We can see that the items have more or less similarities but few elements are owned by all of them. Members of a category have different status and prototype is referred to as the most typical member of the category. Prototype plays an extremely important role in understanding the category, just as Ungerer and Schmid (2008:16) point that "prototypes have a crucial function in the various stages involved in the formation and learning of categories"

Prototype theory can explain the forming of polysemous words. Prototype theory believes that the meaning of a word is expanded on the basis of prototype and then forms a semantic network. In the same concept network the status of the internal members are not equal, so that it can explain the semantic extension of vocabulary.

\section{B. Image Schema}

Besides category, there is another cognition level about the relations between different things and Lakoff called that "kinesthetic image schema" or simply "image schema" (Zhao Yanfang, 2002). Image schema is a kind of cognition structure which derived from human's experience and interaction with the world. If we have the same or similar experience for several times, we'll get some kind of cognitive schema of such experience which we can apply to other similar instances. As the term suggests, image schema is actually a mental picture. The picture is more understandable than abstract principles and it is more fundamental than concrete categories. There are various kinds of image schemas in our world, like the IN-OUT schema, UP-DOWN schema, etc. Image is an integrated whole which we can use to comprehend the abstract vocabulary.

\section{Conceptual Metaphor}

Based on image, there is another cognitive phenomenon called metaphor. Metaphors are not only regarded as figures of speech, but the main cognitive ways to form human's conceptual system. Cognitive linguistics holds that they are powerful tools for us to conceptualize the abstract categories around us. Metaphors usually involve a mapping from concrete source domain to abstract target domain and in this way metaphors can extend the sources of a language. Cognitive linguists think that metaphors are not only linguistic but also cognitive. The nature of metaphor is to perceive an abstract thing with the help of one thing we are familiar with. Lakoff believes that our daily activities, including vocabulary study, are metaphorical. Metaphor has become our thinking method and it gives us powerful help for us to explore the world around us. One of the influences of conceptual metaphor on vocabulary is that it receives a lot of daily vocabulary into metaphor and it becomes the main cognitive mechanism behind the phenomenon of polysemous words.

\section{COGNITIVE ENGLISH VocABULARY TEACHING STRATEGIES}

\section{A. Prototype-based Teaching Strategy}

The contribution of prototype theory to English vocabulary teaching is that the theory puts its emphasis on the status of English vocabulary. In English vocabulary, some words are core words while others are brink words. Category division is necessary for human to learn English vocabulary, and prototype lexicon is the very typical, simple word which has direct relationship with human being and can be recognized most easily.

The basic objects which have marked features make up the basic-level category. Above it is the high-level category with more general and abstract features. Below the basic-level category is the low-level category with more specific and less generalized features. English vocabulary is a huge word network with high-level category, low-level category and basic-level category, so the prototype theory can be used into English vocabulary teaching. Category in prototype produces vocabulary category and decides the order of vocabulary production and development, so here comes vocabulary hierarchy. The high-level category vocabulary and low-level category vocabulary are produced on the basis of basic-level category vocabulary, so the status of basic-level category is of vital importance. Generally speaking, basic-level category vocabulary is simple in form and is used more frequently, so it has an irreplaceable role in constituting lexicons. The basiclevel category vocabulary is limited, but words constituted based on basic-level category words are unlimited. In English acquisition, learners usually master the simple basic vocabulary first and apply them to communication. It has been proved that the ability of English learners heavily depends on the basic-level category vocabulary they master. In English teaching practice, teachers should pay more attention to basiclevel category vocabulary. According to the research statistics, people can understand $80 \%$ of an article if they acquire 1000 basic words, 89\% contents with 2000 basic words, 93\% contents with 3000 basic words, etc. (Xu Dekai, 2009)

We can also explain polysemy in English with the theory. For every English polysemy, there is a core meaning and other related meanings extended form the core meaning. We humans often start out from ourselves and our own concrete behaviors to describe other objects and other abstract concepts. Therefore, when teachers explain the meanings of polysemy related to our human body, it's better for them to explain the cognitive process of the word's semantic development as a prototype. Take a simple instance, the word "body" originally refers to our physical parts, including our heads, arms and legs, and gradually it is used to refer to the main part of other objects, such as a car or a building. Then the word is applied to a large area of water, the main part of a document or a thesis, an organized group of people who deal with something officially. The simple word "body" has so many meanings that it becomes a polysemy. In such English vocabulary teaching situation, it's a good idea for teachers to explain the basic meaning first and then deduce other meanings from it. The hierarchical theory in the prototype theory can give students a good foundation of vocabulary study. 
Therefore, in the process of English vocabulary teaching, we should try to teach the basic-level category vocabulary to master the simple and general and frequently used vocabulary. Then the complex and irregular vocabulary will be easier to teach. The basic vocabulary, as the category prototype, has more common characteristics which is helpful for acquisition of other words. Meanwhile, the core meaning of the polysemy should be explained first and then the extended meanings of the word can be understood more easily. This is one of the most effective vocabulary teaching strategies.

\section{B. Image Schema-based Vocabulary Teaching Strategy}

In English vocabulary teaching, it's better to help students establish an image schema of vocabulary to improve their cognitive abilities of English.

Traditional pedagogical approaches always ignore the underlying relations among different meanings of English propositions, but image schema in cognitive linguistics will clearly manifest the relations and differences between different meanings. Most English propositions follow the image schema theory. Let's take "over" for example. Cognitive linguistics holds the word "over" has three kinds of meanings and explains the cognition process of meaning extension. The three meanings are:

- the trajector is across an open place, and maybe contact the landmark. Eg: Planes fly over every 10 or 15 minutes.

- the trajector covers the landmark completely. Eg: The lake is frozen over.

- the trajector falls downwards and outwards from an upright position. Eg: She pushed past me, almost knocking me over.

Among these three kinds of meanings, the first one is the core meaning and it can be regarded as the prototype. The second and the third provide the core meaning for the extension of their own groups, and they are the prototypes of their respective groups. The schema -OVER- represents a cognitive configuration consisting of three elements which are mentioned above and their interrelations. They are the trajector, that is the object which moves, its path and the landmark. The first kind of meaning is a very typical case that applies for many verbs of motion, that is, contact between trajector and landmark. The second one shows that the trajector may have the same or similar size or shape with the landmark so that it can cover the landmark. The third one should probably be regarded as the margin case, the fusion of the trajector and the landmark. I am the trajector that is moved along a path and at the same time the landmark acts as reference point for the motion. The landmarks are various, so the relations between the trajector and the landmark will vary, too. The landmark can be extending or vertical, or both vertical and extending. The trajectors also have many characters. They can be moving or static, or in contact with the landmark, or have no touch with the landmark. Sometimes they can even completely cover the landmark. As a result, in different sentences "over" may have the above three semantic prototypes with their own additional semantic features.
According to the above explanation we can get familiar with the usages of "over" in different contexts. By the strategy of image schema we can master the accurate meanings of the propositions and improve the cognitive ability about English. Therefore the new horizon of cognitive linguistics provides us with image schema to show the construction of polysemy and that gives us a good guide to identify the underlying link between the polysemy.

\section{Metaphor-based Vocabulary Teaching Strategy}

Cultivating the thinking mode of metaphor to improve students' capacity of understanding polysemy is a good method for English teachers.

Life, as well as language, is full of metaphors. We can hardly acquire a language, including English if we ignore metaphors. To learn metaphors in English well will help learners master English better. In the process of English teaching, teachers should explain the metaphoric meanings of words in addition to their basic meanings. That skill requires teachers perceive the implicit conceptual metaphor through the phenomena, and connect the metaphor to its corresponding expressions. When words are introduced to English learners, special attention should be paid to the basic-level category words, because they are rich in metaphorical meanings. It is suggested that the basic meanings of words taught first and then the underlying link between the basic meanings and the metaphorical ones shown. Only the learners have a deep understanding about the basic meanings, can they master the metaphorical meanings better. For example, when teachers explain the word "conceive" which has different meanings such as "pregnant" and "imagine", it is advisable to teach the concrete meaning "pregnant". We all know that metaphor is a mapping of structure from the source domain to target domain. Therefore, the metaphor mapping can be established between "pregnant" and "imagine". Being "pregnant" means getting a baby in the belly while "imagine" something means that you get some plans or ideas in your brain, just like the baby in the belly.

English has enormous vocabulary and every word has many different meanings and these meanings are not random. About seventy percent of the meanings of English words are metaphors or are derived from metaphors. For instance, the word "crawl" describes the forward movement on hands and knees. When people crawl, the speed is very slow, so the word "crawl" has an extended meaning, that is "moving slowly" regardless of the means of movement. The metaphorical meaning "moving slowly" can refer to the slow motion of the vehicle, cloud, fog and water, etc. On this basis, "crawl" can be used to express the slow motion of anything, including the abstract concepts. For example, The days were crawling past. In the sentence, "crawl" is used to describe that time passed slowly. Let's look at another example, She crawled down the list of names checking each one carefully. Here "crawl" can be understood as the gesture of groveling to other people. Therefore, "crawl" get another metaphorical meaning "grovel".

This English vocabulary teaching strategy suggests that teachers explain the metaphorical relationship between the different meanings of a word. Learners should be helped to 
realize that the meanings of a specific word are not random, and to have a deep understanding about the metaphor mechanism. In this way, students won't recite the meanings mechanically, but master and apply the words more effectively.

Besides the three strategies we mentioned above, some necessary assistant strategies are also suggested. In order to achieve a better vocabulary proficiency in English vocabulary teaching, teachers should combine the new meanings of words with the old meanings and pay attention to students' experience memory. Furthermore, teachers had better help students improve their cognitive abilities and enrich students' culture background knowledge.

\section{CONCLUSION}

This paper puts emphasis on a new vocabulary teaching model based on cognitive linguistics. The theoretical basis of cognitive linguistics is embodied philosophy which holds the view that language is formed on the basis of bodily experience of the reality and by means of cognitive process, and language is the result of interaction between the subjects and the world. From the cognitive perspective we put forward some cognitive theories, including the prototype theory, image schema and metaphor theory. Based on these theories, some English vocabulary teaching strategies and examples are also presented to illustrate the application of cognitive linguistic theories. Application of cognitive linguistics in English vocabulary teaching can help students understand the vocabulary better, help students use English vocabulary well. We can say that cognitive linguistics is an excellent and innovative way to teach English vocabulary.

However, it doesn't mean that traditional teaching method will be abandoned. Indeed cognitive linguistics has some advantages about vocabulary teaching over traditional way, but it can't solve all the problems in English vocabulary teaching. When using the cognitive approach, we'd better get familiar with its limits to guide students learn vocabulary well.

\section{REFERENCES}

[1] Geeraerts, Dirk. (2006). Cognitive Linguistics: Basic Readings. Berlin: Mouton de Gruyter.

[2] Harmer, Jeremy. (2004). How to Teach English. Beijing: Foreign Language Teaching and Researching Press.

[3] Lakoff, G.\&M. Johnson. Metaphors We Live By. Chicago: University of Chicago Press, 1980: 132-138.

[4] Rosch, E. 1978. Principles of Categorization. Cognition and Categorization [C], ed. by E. and B.Lloyd. Hillsadale, NJ:elbaum. Pp.36

[5] Ungerer, F. \&H.-J. Schmid. An Introduction to Cognitive Lingusitics. Beijing: Foreign Language Teaching and Research Press, 2008.

[6] Wilkins,D.A.1976. National Syllabus[M]. Oxford: Oxford University Press

[7] Cao Yongbo. A Study of Applying Cognitive Linguistic Theories to English Vocabulary Pedagogy [D]. Wuhan University of Technology, 2008

[8] Lin Yun. Cognitive Lexical Semantics and the Implications for College English Learning and Teaching $[\mathrm{J}]$. Journal of Huber University of Education, 2011.

[9] Wang Yin. Semantic Theory and Language Teaching [M]. Shanghai: Shanghai Foreign Language Education Press, 2003.
[10] Xiong Yanbing. The Inspirations of Cognitive Linguistics for ESL Vocabulary Teaching [D]. Wuhan University of Technology, 2006.

[11] Xu Dekai. College English Vocabulary Teaching Theory and Practice [M]. Changchun: Jilin Publishing Group Co., Ltd. 2009.

[12] Zhang Shaoquan. Lexical Semantic Change and Its Motivations and Cognitive Mechanisms [J], Foreign Language Research, 2010, (1): 31 35

[13] Zhao Yanfang. An Introduction to Cognitive Linguistics [M]. Shanghai: Shanghai Foreign Language Education Press, 2002, 68-70. 